\title{
Device Fell
}

National Cancer Institute

\section{Source}

National Cancer Institute. Device Fell. NCI Thesaurus. Code C133516.

Problem associated with the device or a component unexpectedly being dropped or moving down from an intended place. 